\title{
The Role of CHI3L1 Expression in Angiogenesis in Invasive Ductal Breast Carcinoma
}

\author{
AGNIESZKA RUSAK ${ }^{1}$, KAROLINA JABLONSKA ${ }^{1}$, ALEKSANDRA PIOTROWSKA ${ }^{1}$, \\ JEDRZEJ GRZEGRZOLKA ${ }^{1}$, ALEKSANDRA NOWAK ${ }^{1}$, ANDRZEJ WOJNAR ${ }^{2}$ and PIOTR DZIEGIEL ${ }^{1,3}$ \\ ${ }^{1}$ Division of Histology and Embryology, Department of Human Morphology and Embryology, \\ Wroclaw Medical University, Wroclaw, Poland; \\ ${ }^{2}$ Department of Pathology, Lower Silesian Oncology Center, Wroclaw, Poland; \\ ${ }^{3}$ Department of Physiotherapy, University School of Physical Education, Wroclaw, Poland
}

\begin{abstract}
Background/Aim: An increased level of chitinase 3 like 1 protein $(\mathrm{CHI}$ Ll) expression is observed in patients with cancer and may have potential prognostic value. The aim of this study was to evaluate the role of CHI3L1 in angiogenesis in invasive ductal breast carcinoma $(I D C)(n=110)$. Materials and Methods: Immunohistochemistry was used to assess the expression of CHI3L1, CD31, CD34, vascular endothelial growth factor (VEGFA, VEGFC and VEGFD). Real-time polymerase chain reaction and western blot were used to determine the level of CHI3L1 mRNA and protein. Results: Immunohistochemistry demonstrated positive correlation between $C H I 3 L 1$ expression and angiogenesis markers: $C D 31$ $(r=0.34, p=0.0003), C D 34 \quad(r=0.24, p=0.012), V E G F D$ $(r=0.24, p=0.013)$. Higher CHI3L1 expression in estrogen receptor-negative $(p=0.041)$ and progesterone receptornegative $(p=0.014)$ cancer was observed. Higher CHI3LI expression was reported in cancer tissues in comparison to non-malignant breast lesions. Conclusion: These results suggest a potential role of CHI3L1 in angiogenesis in IDC and may suggest its involvement in cancer progression.
\end{abstract}

Breast cancer is one of the most frequently diagnosed cancers in women. According to World Health Organization data, breast cancer is the cause of death of more than 0.5 million women each year (1). Despite significant advances in breast cancer diagnostics and therapy, the search for new biomarkers with potential prognostic value is still important.

Correspondence to: Agnieszka Rusak, Division of Histology and Embryology, Department of Human Morphology and Embryology, Wroclaw Medical University, T. Chalubinskiego 6a, 50-368 Wroclaw, Poland. Tel: +48 717841354(55), Fax: +48 717840082, e-mail: rusakagn@gmail.com

Key Words: CHI3L1, YKL40 angiogenesis, breast cancer.
Chitinase 3 like 1 (CHI3L1, YKL40, Cgp-39) is a catalytically inactive protein with a mass of about $40 \mathrm{kDa}$. It belongs to the family of chitinase-like proteins (CLPs), which are structurally homologous to chitinases (2, 3). CLPs are classified as lectins, which are molecules with characteristics of growth factors and cytokines (4). As a secretory protein, CHI3L1 can act locally and systemically, and this may be associated with its uneven tissue distribution $(5,6)$.

An increased level of CHI3L1 is not specific to any particular disease and it may suggest an inflammation- or cancer-related process in the body $(4,7)$. An elevated level of CHI3L1 was observed in serum of patients suffering from inflammation of various etiologies: multiple sclerosis, rheumatoid arthritis and asthma (7-10). Numerous reports describe an increased level of CHI3L1 in serum and cancerous tissue of patients with e.g. glioma, breast, lung, colonic and ovarian cancer (11-16). It was shown that CHI3L1 is expressed in both cancer cells and tumorassociated macrophages $(2,17,18)$. CHI3L1 may play a role in cancer by involvement in the formation of new blood vessels, regulation of stromal cells and modulation of inflammation of the tumor microenvironment (19-22).

Angiogenesis is a key process determining tumor growth. According to the definition given by Folkman in 1972, angiogenesis is the formation of new blood vessels from existing ones (23). Several pro-angiogenic factors are involved in this process, e.g.: vascular endothelial growth factor (VEGF), cytokines (interleukin: IL1, IL4, IL6, IL8), endogenous modulators (IL13, integrin $\alpha v \beta 3$, hypoxia), as well as angiogenesis inhibitors, such as tissue inhibitors of metalloproteinases and cytokines (IL10, IL12, IFN $\gamma$ ) (24-26).

In clinical practice, inhibition of angiogenesis is used in addition to chemotherapy (e.g. the monoclonal antibody to VEGF, bevacizumab) in breast cancer, colorectal cancer and gliomas for example $(26,27)$. Recently, the role of the 
normal structure of newly formed blood vessels is emphasized in anticancer therapy in addition to direct antiangiogenic activities (28-31). Correct remodeling of blood vessels requires sealing the blood vessel walls by enhancing intercellular connections in the endothelium and increasing the number of pericytes that cover the blood vessel walls $(29,30)$. This process is believed to a crucial role in more efficient transport of chemotherapeutics into the tumor environment, increasing penetration of immune cells and reducing cancer cell migration $(28,30)$. It is suggested that this effect may be associated with anti-VEGF therapy and thus it could possibly increase efficacy of combined cytostatic treatment. The activity of potential regulators of blood vessel remodeling, including platelet derived growth factor receptor beta $(\mathrm{PDGFR} \beta)$, regulator of $\mathrm{G}$ protein signaling 5 (RGS5), angiopoietin-1 and-2 (ANGPT1/2) and transforming growth factor beta 1 (TGFB1), is emphasized in the literature (28).

Through heparan sulfate (HS) chains, CHI3L1 binds to syndecan 1 (SDC1) on the surface of endothelial cells, thus activating interactions between SDC1 and integrin $\alpha v \beta 3$ and vascular endothelial cadherin. As a consequence of these interactions, protein tyrosine kinase 2- mitogen-activated protein kinase 1/3 (PTK2-MAPK1/3) signaling pathway is activated and affects expression of genes encoding proangiogenic factors such as VEGF receptor 2. CHI3L1 may also affect stability of newly formed vessels, as it influences conjugation of SDC1 with vascular endothelial cadherin, which then recruits $\beta$-catenin and cytoskeletal actin. Additionally, CHI3L1 may induce SDC1 binding to Ncadherin, intracellular $\beta$-catenin and smooth muscle $\alpha$-actin in vascular smooth muscle cells and pericytes, which leads to increased cell adhesion and vessel sealing $(19,24)$. It is believed that CHI3L1 may also promote angiogenesis by interactions with interleukin 13 receptor (IL13R $\alpha 2$ ) on the surface of cancer cell, thus leading to the activation of the phosphatidylinositol 3-kinase and AKT serine/threonine kinase (PI3K/AKT) pathway $(19,33)$.

The aim of the present study was to investigate the potential effects of CHI3L1 on angiogenesis by evaluation of the correlation between CHI3L1 expression and selected markers of angiogenesis in invasive ductal breast carcinoma (IDC).

\section{Materials and Methods}

Patients and tumors. The study was conducted using specimens from patients with IDC diagnosed between 1999-2009 $(n=110)$ which were retrieved from the Lower Silesian Oncology Centre in Wroclaw. Specimens of non-malignant breast tissue lesions (NBTLs) $(\mathrm{n}=25)$ were the control material for this study. Table I shows the clinicopathological characteristics of patients. All studies were conducted with the consent of Ethics Committee of Wroclaw Medical University (approval: KB-616/2014 and KB-735/2017).
Immunohistochemistry (IHC). Collected IDC fragments were fixed in $4 \%$ buffered formalin and embedded in paraffin. IHC reactions were performed using Dako Autostainer Link48 (Dako, Glostrup, Denmark) on $4 \mu \mathrm{m}$-thick paraffin sections. Deparaffinization, rehydration and epitope retrieval $\left(97^{\circ} \mathrm{C}, 20 \mathrm{~min}\right)$ were performed using PT-Link (Dako) in EnVision ${ }^{\mathrm{TM}}$ FLEX Target Retrieval Solution High pH (9.0) (Dako) for antibodies to CHI3L1, VEGFA, VEGFD, CD31, CD34, estrogen receptor $(\mathrm{ER})$, progesterone receptor $(\mathrm{PR})$ and human epidermal growth factor receptor 2 (HER2), whereas EnVision ${ }^{\mathrm{TM}}$ FLEX Target Retrival Solution Low pH (6.0) (Dako) was used for antibodies to VEGF-C and Ki-67. Endogenous peroxidase was blocked using EnVision $^{\mathrm{TM}}$ FLEX Peroxidase-Blocking Reagent (Dako) (5 min). LSAB+ detection system (Dako) was used to visualize IHC reactions performed with the use of goat polyclonal antibodies to CHI3L1 (1:100, $20 \mathrm{~min}$, room temperature (RT); R\&D Systems, Minneapolis, MN USA), VEGF-C (1:100, $18 \mathrm{~h}, 4^{\circ} \mathrm{C}$; ReliaTech $\mathrm{GmbH}$, Braunschweig, Germany) and VEGF-D $\left(1: 100,18 \mathrm{~h}, 4^{\circ} \mathrm{C}\right.$; ReliaTech $\mathrm{GmbH})$. For visualization of IHC reactions performed with the use of mouse monoclonal antibodies (Dako): CD31 (ready-to-use; $20 \mathrm{~min}$, RT), CD34 (ready-to-use; $20 \mathrm{~min}, \mathrm{RT})$, VEGFA (1:50, $\left.18 \mathrm{~h}, 4^{\circ} \mathrm{C}\right), \mathrm{Ki}$ 67 (RTU, $20 \mathrm{~min}, \mathrm{RT}$ ), ER (ready-to-use; $20 \mathrm{~min}, \mathrm{RT}$ ) and PR (readyto-use; 20 min, RT), EnVision ${ }^{\mathrm{TM}}$ FLEX $^{+}$, Mouse, High pH (Dako) system was used. HercepTest ${ }^{\mathrm{TM}}$ kit (Dako) was used to measure expression of HER2. Sections were counterstained with hematoxylin (EnVision $^{\text {TM }}$ FLEX Hematoxylin; Dako). The visualization systems were used according to the manufacturer's instructions.

Evaluation of IHC reactions. IHC reactions were analyzed using light microscopy (BX41; Olympus, Tokyo, Japan). Intensities of CHI3L1, VEGFA, VEGFC and VEGFD expression were evaluated using semiquantitative, 12-point Immunoreactive Score according to Remmele and Stegner (34) (Table II). Median values were used as the cut-off points. Low CHI3L1 expression was assigned to cases with 0-3 IRS, whereas high expression of this protein was assigned to cases with 412 IRS. For VEGFA, VEGFC, and VEGFD, scores of 0-4 IRS were considered to indicate low expression, while scores of 6-12 IRS indicated high expression of these proteins. Relative microvessel count (MVC) was estimated for CD31- and CD34-labelled blood vessels using a Chalkley eyepiece (Pyser Sgi., Edenbridge, UK), based on the number of grid points $(n=1-25)$ that hit stained microvessels (35-37). Relative MVC was estimated as the mean value of three hot-spots characterized by the most intense vascularization (magnification $\times 200)(35)$. The expression of Ki-67 was estimated using a semi-quantitative scale with the values of $0-4: 0$ : $0 \%$ of positive cells, $1: 1-10 \%$ of positive cells, $2: 11-25 \%$ of positive cells, 3: $26-50 \%$ of positive cells, $4: 51-100 \%$ of positive cells (38). For Ki67 , values for $\leq 25 \%$ of positive cells were considered to indicate low expression, while those $>25 \%$ indicated high expression of this protein. Expressions of ER, PR and HER2 were evaluated using semiquantitative $0-3$ score: 0 : $0 \%$ of positive cells, 1 : $1-10 \%$ of positive cells, 2: $11-50 \%$ of positive cells, $3: 51-100 \%$ of positive cells. For ER and PR, the reaction was considered positive when values $\geq 1 \%$ of immunopositive cells (as indicated by the score of 1 or higher) (39). Reaction for HER2 was deemed positive when $>10 \%$ of cancer cells showed intensive membrane reaction (the score of 3) (40).

Real-time PCR. Fragments of grade $1(\mathrm{n}=6)$, grade $2(\mathrm{n}=20)$ and grade $3(n=20)$ IDC tumors were fixed in RNAlater (Qiagen, Hilden, Germany) and stored at $-80^{\circ} \mathrm{C}$. The mRNA was isolated using RNeasy Mini Kit (according to the manufacturer's protocol). High Capacity 
Table I. Chitinase 3 like 1 (CHI3L1) protein expression as immunoreactive score (IRS) according to clinicopathological factors. Median values were used as the cut-off point; Fisher test.

\begin{tabular}{|c|c|c|c|c|c|c|c|c|}
\hline \multirow[b]{2}{*}{ Parameter } & & \multicolumn{2}{|c|}{ Overall } & \multicolumn{2}{|c|}{ IRS (0-3) } & \multicolumn{2}{|c|}{ IRS (4-12) } & \multirow[b]{2}{*}{$p$-Value } \\
\hline & & $\mathrm{N}$ & $\%$ & $\mathrm{~N}$ & $\%$ & $\mathrm{~N}$ & $\%$ & \\
\hline \multirow[t]{3}{*}{ Age } & $>50$ Years & 75 & 68.2 & 47 & 62.7 & 28 & 37.3 & 0.670 \\
\hline & $\leq 50$ Years & 35 & 31.8 & 24 & 68.6 & 11 & 31.4 & \\
\hline & Total & 110 & 100 & 71 & 64.5 & 39 & 35.5 & \\
\hline \multirow[t]{3}{*}{ Menopausal status } & Pre- & 33 & 30 & 24 & 72.7 & 9 & 27.3 & 0.378 \\
\hline & Post- & 70 & 63.6 & 44 & 62.9 & 26 & 37.1 & \\
\hline & Unknown & 7 & 6.4 & 3 & 42.9 & 4 & 57.1 & \\
\hline \multirow[t]{4}{*}{ Tumor grade } & 1 & 9 & 8.2 & 5 & 55.6 & 4 & 44.4 & 0.393 \\
\hline & 2 & 55 & 50 & 39 & 70.9 & 16 & 29.1 & \\
\hline & 3 & 44 & 40 & 26 & 59.1 & 18 & 40.9 & \\
\hline & Unknown & 2 & 1.8 & 2 & 100 & 0 & 0 & \\
\hline \multirow[t]{5}{*}{ Stage } & I & 33 & 30 & 23 & 69.7 & 10 & 30.3 & 0.347 \\
\hline & II & 54 & 49.1 & 32 & 59.3 & 22 & 40.7 & \\
\hline & III & 13 & 11.8 & 11 & 84.6 & 2 & 15.4 & \\
\hline & IV & 3 & 2.7 & 2 & 66.7 & 1 & 33.3 & \\
\hline & Unknown & 7 & 6.4 & 3 & 42.9 & 4 & 57.1 & \\
\hline \multirow[t]{4}{*}{ Tumor size } & pT1 & 53 & 48.2 & 33 & 62.3 & 20 & 37.7 & 0.926 \\
\hline & pT2 & 46 & 41.8 & 30 & 65.2 & 16 & 34.8 & \\
\hline & pT3 & 7 & 6.4 & 5 & 71.4 & 2 & 28.6 & \\
\hline & pT4 & 4 & 3.6 & 3 & 75 & 1 & 25 & \\
\hline \multirow[t]{5}{*}{ Lymph node } & pNO & 63 & 57.3 & 42 & 66.7 & 21 & 33.3 & 0.528 \\
\hline & $\mathrm{pN} 1$ & 35 & 31.8 & 20 & 57.1 & 15 & 42.9 & \\
\hline & $\mathrm{pN} 2$ & 6 & 5.5 & 5 & 83.3 & 1 & 16.7 & \\
\hline & $\mathrm{pN} 3$ & 4 & 3.6 & 2 & 50 & 2 & 50 & \\
\hline & Unknown & 2 & 1.8 & 2 & 100 & 0 & 0 & 0.176 \\
\hline \multirow[t]{3}{*}{ ER status } & Negative & 30 & 27.3 & 17 & 56.7 & 13 & 43.3 & \\
\hline & Positive & 72 & 65.4 & 51 & 70.8 & 21 & 29.2 & \\
\hline & Unknown & 8 & 7.3 & 3 & 37.5 & 5 & 62.5 & \\
\hline \multirow[t]{3}{*}{ PR status } & Negative & 39 & 35.4 & 21 & 53.8 & 18 & 46.2 & 0.051 \\
\hline & Positive & 63 & 57.3 & 47 & 74.6 & 16 & 25.4 & \\
\hline & Unknown & 8 & 7.3 & 3 & 37.5 & 5 & 62.5 & \\
\hline \multirow[t]{3}{*}{ HER2 status } & Negative & 81 & 73.6 & 51 & 63.0 & 30 & 37.0 & 0.193 \\
\hline & Positive & 21 & 19.1 & 17 & 81.0 & 4 & 19.0 & \\
\hline & Unknown & 8 & 7.3 & 3 & 37.5 & 5 & 62.5 & \\
\hline \multirow[t]{3}{*}{$\mathrm{TN}$} & Yes & 16 & 14.6 & 9 & 56.2 & 7 & 43.8 & 0.380 \\
\hline & No & 80 & 72.7 & 56 & 70.0 & 24 & 30.0 & \\
\hline & Unknown & 14 & 12.7 & 6 & 42.9 & 8 & 57.1 & \\
\hline \multirow[t]{3}{*}{ Ki-67 } & Low $\leq 25 \%$ & 62 & 56.4 & 43 & 69.4 & 19 & 30.6 & 0.821 \\
\hline & High $>25 \%$ & 35 & 31.8 & 23 & 65.7 & 12 & 34.3 & \\
\hline & Unknown & 13 & 11.8 & 5 & 38.5 & 8 & 61.5 & \\
\hline
\end{tabular}

ER: Estrogen receptor, PR: progesterone receptor, HER2: human epidermal growth factor receptor 2, TN: triple-negative (no expression of ER, PR and HER2).

cDNA Reverse Transcription Kit (Applied Biosystems, Carlsbad, CA, USA) was used for reverse transcription. Real-time PCR reaction was performed on cDNA arrays using starters (Applied Biosystems, Carlsbad, CA, USA) for CHI3L1 (Hs00609691_m1) and $\beta$-actin as an endogenous control ( $A C T B$, Hs99999903_m1), TaqMan Gene Expression Master Mix and 7500 Real-Time PCR System (Applied Biosystems). Real-time PCR reaction conditions were: initial denaturation at $50^{\circ} \mathrm{C}$ for $2 \mathrm{~min}, 95^{\circ} \mathrm{C}$ for $10 \mathrm{~min}, 40$ cycles at $95^{\circ} \mathrm{C}$ for $15 \mathrm{~s}$ and $60^{\circ} \mathrm{C}$ for $1 \mathrm{~min}$. The changes in mRNA level in comparison to reference gene $(A C T B)$ were calculated using $\Delta \Delta C$ t method. The experiments were run in triplicates.
Western blot. Frozen samples of IDC with various malignant grades (grade 1: $n=3$, grade 2: $n=9$ and grade 3: $n=10$ ), were homogenised in T-PER Tissue Protein Extraction Reagent with the addition of $0.5 \mathrm{mM}$ phenylmethanesulfonyl fluoride and protease inhibitor $\left(\mathrm{Heat}^{\mathrm{TM}}\right.$ Protease Inhibitor Coctail $\times 100$ ) (all Thermo Scientific, Wilmington, DE, USA). Protein level was determined by colorimetric method with the use of bicinchoninic acid (Pierce BCA Protein Assay Kit) and NanoDrop 1000 (Thermo Scientific). Tissue lysate was denatured in sample buffer [250 mM TRIS pH 6.8, 40\% glycerol, $20 \%$ (v/v) $\beta$ mercaptoethanol, $100 \mathrm{mM}$ 1,4-dithiothreitol, $0.33 \mathrm{mg} / \mathrm{ml}$ bromophenol blue, $8 \%$ sodium dodecyl sulfate (SDS)] for $10 \mathrm{~min}$ at $95^{\circ} \mathrm{C}$. Equal 
Table II. Immunoreactive score (IRS) according to Remmele and Stegner (34). The score is the product of the score for the percentage of positively stained cells (A) and for immunohistochemical reaction intensity $(B)$.

\begin{tabular}{lcc}
\hline Points & $\begin{array}{c}\text { Percentage of positively } \\
\text { stained cells (A) }\end{array}$ & $\begin{array}{c}\text { Intensity of color } \\
\text { reaction (B) }\end{array}$ \\
\hline 0 & $0 \%$ & 0 No color reaction \\
1 & $\leq 10 \%$ & 1 \\
2 & $11-50 \%$ & 2 Moderate intensity \\
3 & $51-80 \%$ & 3 Intense color \\
4 & $>80 \%$ & \\
\hline
\end{tabular}

amounts of protein (30 $\mu \mathrm{g}$ for lane) were subjected to electrophoretic separation in $10 \%$ polyacrylamide gel in Mini Protean 3 apparatus (Bio-Rad, Marnes-la-Coquette, France) according to Laemmli method (41). Next, the proteins were electrophoretically transferred onto a polyvinylidene difluoride membrane (Immobilon; Millipore, Bedford, MA, USA) in Tris-glycine buffer with $20 \%$ methanol and $0.05 \%$ SDS. The membrane was blocked in $4 \%$ bovine serum albumin solution in Tris-buffered saline (TBST) with $0.1 \%$ Tween-20. For detection of CHI3L1 level, goat polyclonal anti-CHI3L1 (1:1000; R\&D Systems) was used; the incubation was carried out overnight at $4^{\circ} \mathrm{C}$. The membrane was washed three times with TBST, $0.2 \%$ TritonX-100, and then incubated with donkey anti-goat antibody conjugated with horseradish peroxidase (HRP) (1:1000, 1 h RT; Jackson ImmunoResearch, Suffolk, UK). The level of CHI3L1 was determined based on semi-quantitative densitometric analysis and normalized against $\beta$-tubulin level, wherein rabbit, polyclonal anti- $\beta$-tubulin ( $1: 1000$, in $0.1 \%$ BSA with TBST; Abcam, Cambridge, UK) and donkey secondary anti-rabbit antibody (1:6000 in TBST, $1 \mathrm{~h} \mathrm{RT}$; Jackson ImmunoResearch) were used to measure $\beta$-tubulin level. Detection was performed using chemiluminescence substrate (Immune-Star ${ }^{\mathrm{TM}}$ HRP kit; Biorad, Hercules, CA, USA). Chemiluminescence was measured with ChemiDoc ${ }^{\mathrm{TM}}$ MP System (Bio-Rad) and with exposure time from $2 \mathrm{~s}$ to $30 \mathrm{~min}$. ImageLab software (Bio-Rad) was used to analyze the results. The experiments were run in triplicates.

Statistical analysis. Analysis of normal distribution of studied characteristics was performed with Shapiro-Wilk test. Statistical analysis of CHI3L1 expression and its correlation with clinicopathological data was performed with Student $t$-test, Fisher and Mann-Whitney $U$-test. Correlation between expression of CHI3L1 and vascular markers was calculated using Spearman rank correlation test. For the analysis of overall (OS) and disease-free survivals (DFS), Kaplan-Meier and log-rank (Mantel-Cox) tests were used. Prism 5.0 (GraphPad, La Jolla, CA, USA) software was used for statistical analysis. In all cases analyzed, $p$-values of less than 0.05 were considered statistically significant.

\section{Results}

Immunohistochemistry. Analysis of IHC reactions showed cytoplasmic localization of CHI3L1 in $74.5 \%(\mathrm{n}=82)$ cases of IDC (Figure 1A-D). A low level of CHI3L1 expression (0-3 IRS points) was shown in $71(64.5 \%)$, and high CHI3L1 expression (4-12 IRS points) was found in 39 $(35.5 \%)$ specimens (Table I). Expression of CD31 and CD34 was confirmed by IHC reaction in vascular endothelial cells (Figure 1E and F), and that allowed for the evaluation of relative MVC in the analyzed carcinomas. Newly formed vessels were stained because of the expression of CD34 antigen, which is a marker of vascular endothelial progenitor cells (36). Expression of angiogenesis markers VEGFA, VEGDC and VEGFD (36) was observed in the cytoplasm of cancer cells (Figure 1G-I). Intensity of IHC reactions for markers, as well as cut-off points (medians) are shown in Table III. Correlation between expression of CHI3L1 and selected clinicopathological factors is shown in Table I. Analysis of CHI3L1 expression in tumors of different grades of malignancy indicates a significantly higher level of this protein in comparison to the controls (NBTLs) $(p=0.035, p=0.018, p<0.0001$, respectively), as well as its higher expression in grade 3 in comparison to grade 2 cancer $(p=0.056)$ (Figure 2A). Fisher test demonstrated a statistically significant difference in the level of CHI3L1 expression depending on PR status $(p=0.051)$. Statistically higher CHI3L1 expression was found in $\mathrm{ER}^{-}$tumors $(p=0.041)$ (Figure $\left.2 \mathrm{~B}\right)$ and in $\mathrm{PR}-$ cases $(p=0.014)$ (Figure 2C). The level of CHI3L1 expression was borderline statistically significant $(p=0.081)$ in triple-negative (TN) tumors $\left(\mathrm{ER}^{-}, \mathrm{PR}^{-}, \mathrm{HER} 2^{-}\right.$) (Figure $2 \mathrm{E})$, however, no differences were found in CHI3L1 expression in relation to HER2 status (Figure 2D). Analysis of correlation of CHI3L1 expression with vascular markers showed statistically significant positive correlations with: CD31 ( $\mathrm{r}=0.34, p=0.0003)$ (Figure 3A), CD34 ( $\mathrm{r}=0.24$, $p=0.012)$ (Figure 3B) and VEGFD ( $\mathrm{r}=0.24, p=0.013)$ (Figure 3C). No correlation was found between expression of CHI3L1 with VEGFA, nor with VEGFC.

The results obtained by our group showed no statistically significant correlation between CHI3L1 expression and OS and DFS times.

Real-time PCR. The results of real-time PCR experiments for tumors of various grades of malignancy indicate higher CHI3L1 mRNA expression in grade 3 in comparison to grade 2 cancer $(p=0.067)$ (Figure 4A). No statistically significant difference was observed in the level of CHI3L1 mRNA between other malignancy grades in the analyzed cases (Figure 4A).

Western blot. Total protein expression was evaluated by western blot and confirmed the presence of CHI3L1 in tumors, however, no statistically significant differences were observed between particular grades of cancer malignancy (Figure 4B). 


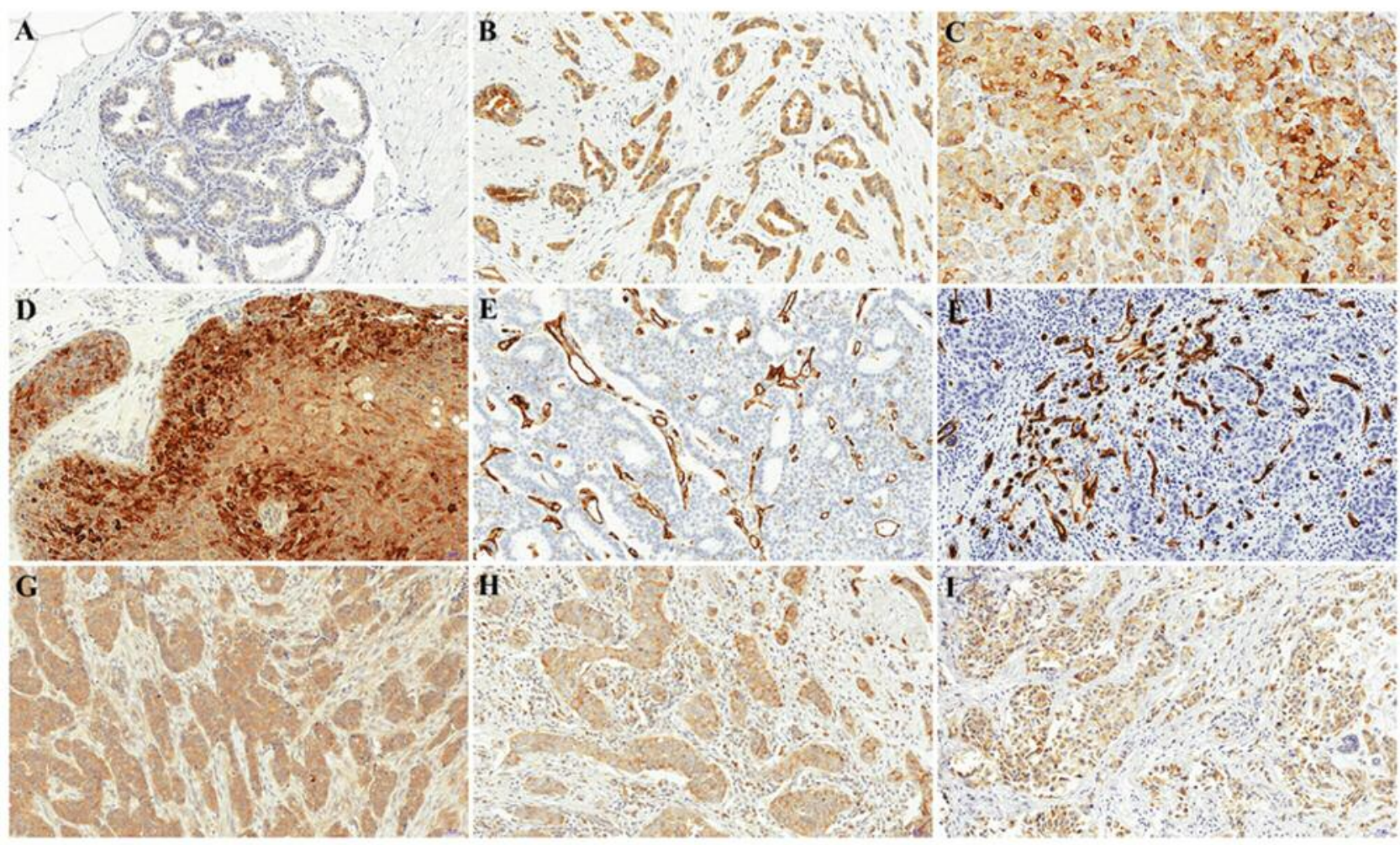

Figure 1. Immunohistochemical reactions performed on paraffin sections of invasive ductal breast carcinoma. Cytoplasmic expression of chitinase 3 like 1 (CHI3L1) protein in breast cancer cells with different grades of malignancy: A: Grade 1: weak, B: grade 2: medium, C: grade 3: medium, and D: grade 3: strong expression. Examples of positive expression of vascular and angiogenesis markers: E: CD31, F: CD34, G: VEGFA: vascular endothelial growth factor A, H: VEGFC, and I: VEGFD. Magnification, $\times 200$.

Table III. The analysis of expression of markers studied in invasive ductal breast carcinoma. Examination of immunohistochemical reactions (IHC) according to the immunoreactive score (IRS) of Remmele and Stegner (34). CD31- and CD34-stained relative microvessel count (MVC) was evaluated using a Chalkley eyepiece. Median values were used as the cut-off points.

\begin{tabular}{|c|c|c|c|c|c|}
\hline \multirow[b]{2}{*}{ IHC marker } & \multirow[b]{2}{*}{ Cut-off value } & \multicolumn{2}{|c|}{ Low expression } & \multicolumn{2}{|c|}{ High expression } \\
\hline & & $(\mathrm{N})$ & $\%$ & $(\mathrm{~N})$ & $\%$ \\
\hline CHI3L1 & IRS 0-3 vs. 4-12 & 71 & 64.5 & 39 & 35.5 \\
\hline VEGFA & IRS 0-4 vs. 6-12 & 69 & 62.7 & 41 & 37.3 \\
\hline VEGFC & IRS 0-4 vs. 6-12 & 73 & 66.4 & 37 & 33.6 \\
\hline VEGFD & IRS 0-4 vs. 6-12 & 70 & 63.6 & 40 & 36.4 \\
\hline MVC CD31 & $\leq 8 v s .>9$ & 61 & 55.5 & 49 & 44.5 \\
\hline MVC CD34 & $\leq 9 v s .>10$ & 66 & 60 & 43 & 40 \\
\hline
\end{tabular}

CHI3L1: Chitinase 3 like 1; VEGFA: vascular endothelial growth factor A; VEGFC: vascular endothelial growth factor C; VEGFD: vascular endothelial growth factor $\mathrm{D}$.

\section{Discussion}

Our studies showed positive correlation between CHI3L1 expression and selected markers of angiogenesis, namely CD31, CD34 and VEGFD, which may suggest a potential role of CHI3L1 in this process in IDC.
These results are in line with an article published by Shao et al., who demonstrated correlation of CHI3L1 with angiogenesis in mouse models of human breast and colon cancer. They found positive correlation between $\mathrm{CD} 31^{+}$and CD $34^{+}$microvessel density (MVD) and CHI3L1 expression (42). They showed significantly greater volume of tumors 

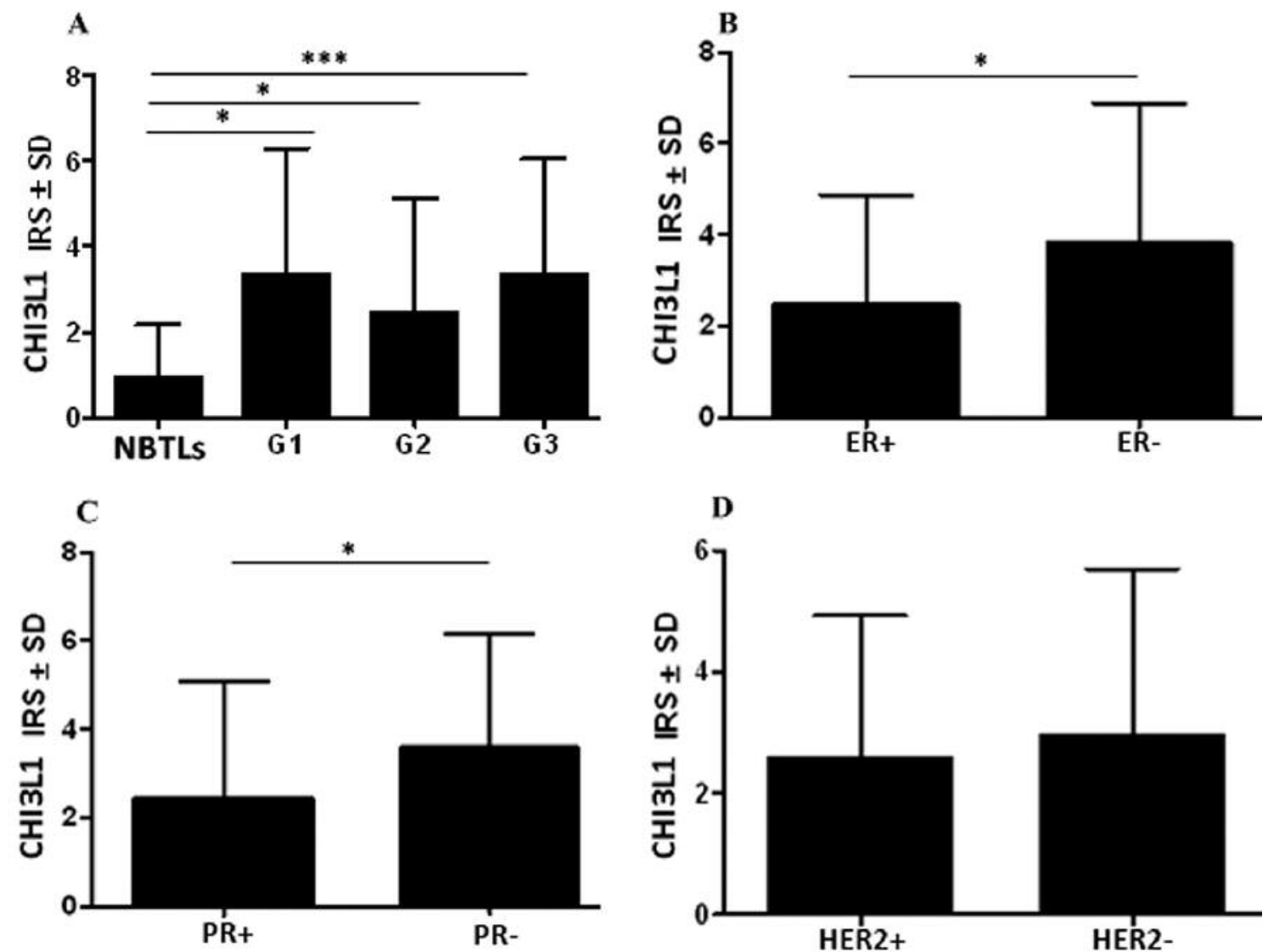

E

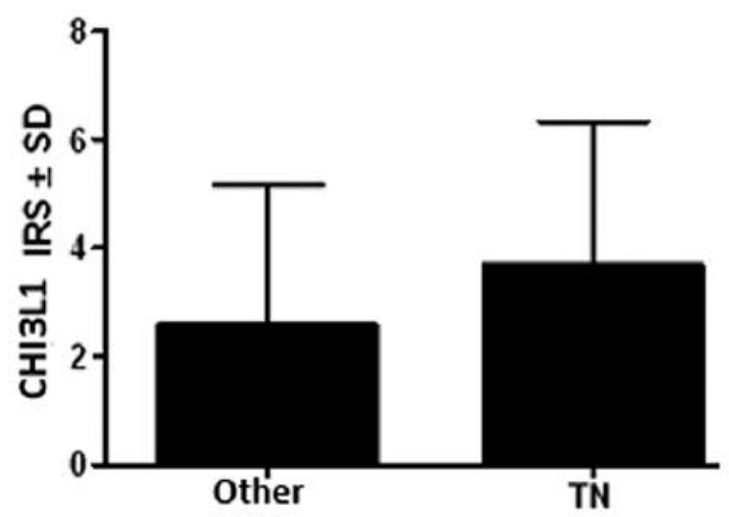

Figure 2. A: Analysis of chitinase 3 like 1 (CHI3L1) protein expression level in invasive ductal breast carcinoma (IDC) relative to non-malignant breast tissue lesions (NBTLs) and according to grade $(G)$ of cancer malignancy. Significantly different at $* p=0.035, * p=0.018$, and $* * * p<0.0001$. Evaluation of CHI3L1 expression level in IDC relative to B: estrogen receptor (ER), C: progesterone receptor (PR), D: human epidermal growth factor-2 receptor (HER2) and E: triple-negative (TN) status. CHI3L1 expression was statistically significantly higher in ER- $(p=0.041)$ and PR( $p=0.014)$ tumors, Mann-Whitney U-test. Data are mean immunoreactive scores (IRS) $\pm S D$.

induced with the use of CHI3L1-overexpressing MDA-MB231 human breast cancer cells. It was also demonstrated that CHI3L1 affects angiogenesis in a VEGF-independent manner by regulating migration or formation of vascular structures by human microvasculature endothelial cells in vitro (42). Additionally, in vitro studies using human U87 glioma cell line and in vivo studies in a mouse model of human glioma and glioma material from patients showed a 

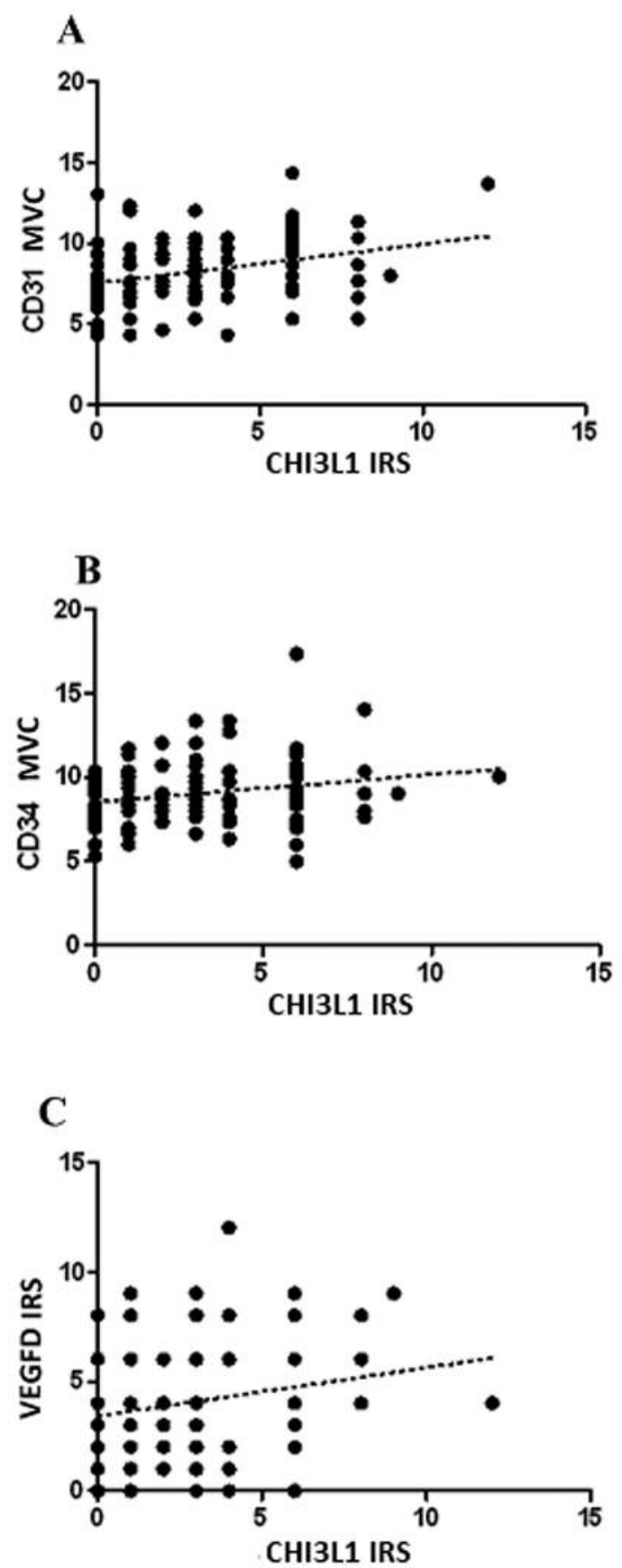

Figure 3. Correlation between chitinase 3 like 1 (CHI3L1) protein expression and angiogenesis markers in invasive ductal breast carcinoma: A: CD31: $r=0.34, p=0.0003 ; B: C D 34: r=0.24, p=0.012$; $C$ : vascular endothelial growth factor D (VEGFD): $r=0.24, p=0.013$; Spearman rank correlation test.

synergistic, pro-angiogenic effect of VEGF and CHI3L1, and suggested a regulatory role of CHI3L1 for VEGF $(32,43)$. In the above studies, silencing of CHI3L1 expression in U87 cells with siRNA showed reduced VEGF expression, thus
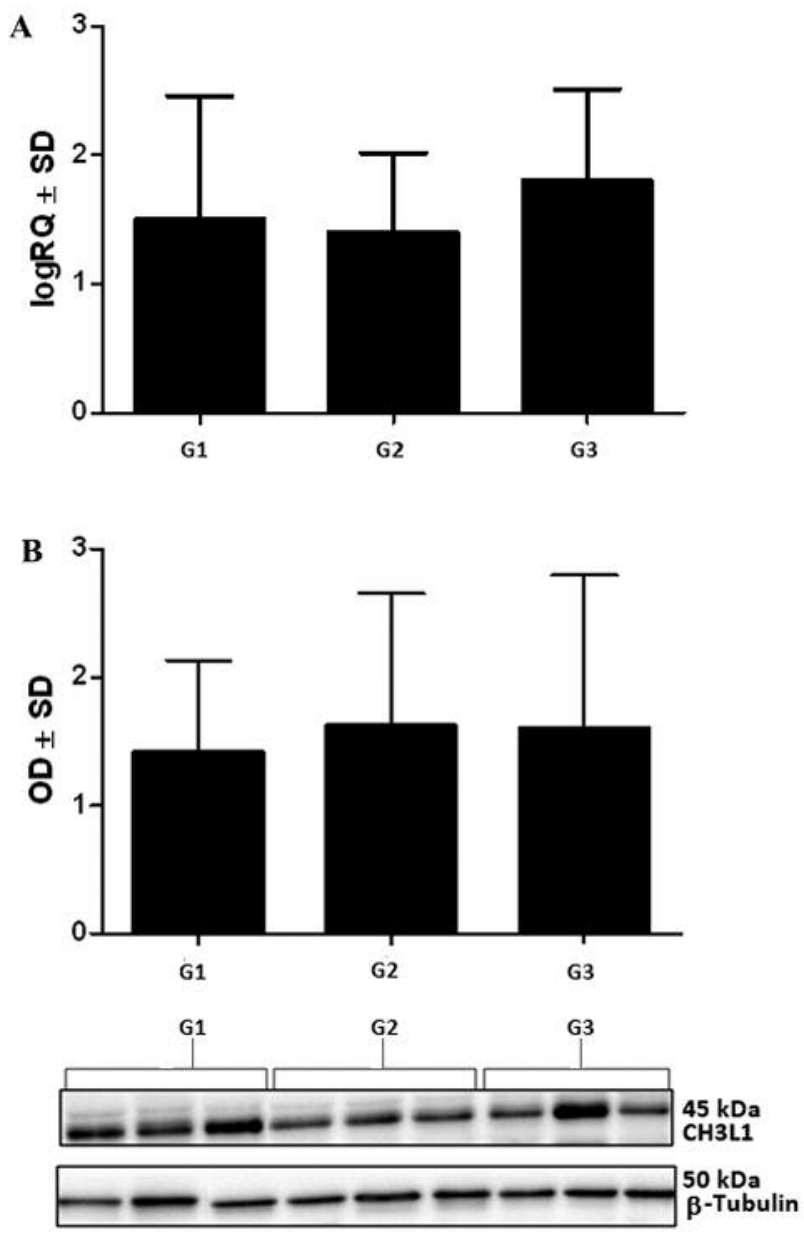

Figure 4. A: Analysis of chitinase 3 like 1 (CHI3L1) mRNA expression level according to grade $(G)$ of cancer malignancy with real-time polymerase chain reaction method. RQ: Relative quantity. $G 1(n=6)$, $G 2(n=20)$ and $G 3(n=20) ; G 2$ vs. G3: $p=0.067$, Student t-test. B: Western blot analysis of CHI3L1 level in tumors with different grades of malignancy: $G 1(n=3), G 2(n=9)$ and $G 3(n=10)$; no statistically significant differences were observed in the level of CHI3L1 between different grades of malignancy: G1 vs. G2: $p=0.791$, G2 vs. G3: $p=0.559, G 1$ vs. G3: p=0.960; Mann-Whitney U-test.

suggesting a regulatory effect of CHI3L1 on VEGF (32). On the other hand, CHI3L1 expression was also induced under extensive VEGF neutralization with the use of antibodies, and this may indicate that CHI3L1 plays an important role in angiogenesis when expression of VEGF is inhibited (32). Angiogenic activity of CHI3L1 was confirmed in in vivo studies performed in a mouse model of human glioma. In those studies, clear inhibition of tumor growth, together with significant reduction in cancer vascularization, was shown in mice that additionally received monoclonal antibody to CHI3L1 in comparison to the control group (32). 
Correlation of increased CHI3L1 expression with $\mathrm{CD} 31^{+}$ MVD and shorter survival time was observed in a mouse model of human glioma. From the therapeutic point of view, it is important that the synergistic effect of combination therapy based on anti-CHI3L1 antibody and radiation therapy or immunotherapy caused a decrease in tumor mass and glioma vascularization, and increased the survival time of mice (43).

$\mathrm{TN}$ breast cancer is characterized by higher blood vessel density in comparison to other types of breast cancer (44, 45). The results obtained by our group show higher CHI3L1 expression in TN IDC cases, which indicates the potential involvement of CHI3L1 in angiogenesis in TN cancer of the highest aggressiveness.

Our results did not show any correlation between CHI3L1 expression and clinicopathological data, such as lymph node metastasis, cancer stage or tumor size, which is in line with observations made by others $(11,46,47)$. However, Kim et al. observed that CHI3L1-expressing tumors were larger than those with no CHI3L1 expression (46). Results from our group showed a higher level of CHI3L1 expression in IDC in comparison to NMBTLs. The lack of a clear statistically significant trend between an increase in cancer grade and the level of CHI3L1 expression may be due to the small number of tumors in analyzed groups.

With the use of other research methods, we confirmed CHI3L1 expression in IDC at the mRNA (real-time PCR) and protein (western blot) levels. The observed tendency for increased CHI3L1 expression in higher cancer grades in the IDCs analyzed suggests the potential role of CHI3L1 in progression of IDC.

The results obtained showed no correlation between CHI3L1 expression and OS and DFS times. This observation is similar to the results of studies carried out with the use of IHC method and IDC material, as shown in Roslind et al. (48), Shao et al. (11), and Kang et al. (47). In accordance with the above literature, our results confirm no prognostic value of CHI3L1 expression in IDC.

Other literature showing statistically significant correlations between increased CHI3L1 expression and shorter OS and DFS are mainly related to studies in which ELISA was performed using serum from patients, and this may explain the differences in the conclusions (49-51). Wan et al. (51) conducted metaanalysis of the role of CHI3L1 in breast cancer that suggested the potential value of $\mathrm{CHI} 3 \mathrm{~L} 1$ as a prognostic factor, particularly for DFS. In addition, the results of this meta-analysis indicated that CHI3L1 may play a role in breast cancer promotion. The authors also point to inconsistencies in the outcome of published publications, various clinicopathological data in the studies, as well as to significant heterogeneity between particular studies, including different methods for the evaluation of CHI3L1 level (IHC, enzyme-linked immunosorbent assay, and radioimmunoassay), different cut-off point values, different subtypes of breast cancer, as well as various cancer stages (51).

\section{Conclusion}

The level of CHI3L1, as measured by IHC staining, appears to have no prognostic value for OS and DFS. Further studies are necessary for better understanding of the role of CHI3L 1 in breast cancer biology.

\section{Conflicts of Interest}

The Authors declare that they have no competing interests in regard to this study.

\section{References}

1 Torre LA, Islami F, Siegel RL, Ward EM and Jemal A: Global cancer in women: Burden and trends. Cancer Epidemiol Biomarkers Prev 26(4): 444-457, 2017.

2 Renkema GH, Boot RG, Au FL, Donker-Koopman WE, Strijland A, Muijsers AO, Hrebicek M and Aerts JM: Chitotriosidase, a chitinase, and the 39-kDa human cartilage glycoprotein, a chitinbinding lectin, are homologues of family 18 glycosyl hydrolases secreted by human macrophages. Eur J Biochem 251(1-2): 504509, 1998.

3 Johansen JS, Williamson MK, Rice JS and Price PA: Identification of proteins secreted by human osteoblastic cells in culture. J Bone Miner Res 7(5): 501-512, 1992.

4 Kzhyshkowska J, Gratchev A and Goerdt S: Human chitinases and chitinase-like proteins as indicators for inflammation and cancer. Biomark Insights 2: 128-146, 2007.

5 Johansen JS, Lottenburger T, Nielsen HJ, Jensen JE, Svendsen MN, Kollerup G and Christensen IJ: Diurnal, weekly, and long-time variation in serum concentrations of YKL-40 in healthy subjects. Cancer Epidemiol Biomarkers Prev 17(10): 2603-2608, 2008.

6 Scully S, Yan W, Bentley B, Cao QJ and Shao R: Inhibitory activity of ykl-40 in mammary epithelial cell differentiation and polarization induced by lactogenic hormones: A role in mammary tissue involution. PLoS One 6(10): e25819, 2011.

7 Malmeström C, Axelsson M, Lycke J, Zetterberg H, Blennow K and Olsson B: Csf levels of YKL-40 are increased in MS and replaces with immunosuppressive treatment. J Neuroimmunol 269(1-2): 87-89, 2014.

8 Knudsen LS, Klarlund M, Skjødt H, Jensen T, Ostergaard M, Jensen KE, Hansen MS, Hetland ML, Nielsen HJ and Johansen JS: Biomarkers of inflammation in patients with unclassified polyarthritis and early rheumatoid arthritis. Relationship to disease activity and radiographic outcome. J Rheumatol 35(7): 1277-1287, 2008.

9 Kazakova MH, Batalov AZ, Mateva NG, Kolarov ZG and Sarafian VS: YKL-40 and cytokines- A new diagnostic constellation in rheumatoid arthritis? Folia Med (Plovdiv) 59(1): 37-42, 2017.

10 Saba M, Sharif MR, Akbari H, Nikoueinejad H and Ramazani Jolfaii M: YKL-40 in asthma and its correlation with different clinical parameters. Iran J Allergy Asthma Immunol 13(4): 271277, 2014.

11 Shao R, Cao QJ, Arenas RB, Bigelow C, Bentley B and Yan W: Breast cancer expression of YKL-40 correlates with tumour grade, poor differentiation, and other cancer markers. $\mathrm{Br} \mathrm{J}$ Cancer 105(8): 1203-1209, 2011. 
12 Roslind A, Johansen JS, Junker N, Nielsen DL, Dzaferi H, Price PA and Balslev E: YKL-40 expression in benign and malignant lesions of the breast: A methodologic study. Appl Immunohistochem Mol Morphol 15(4): 371-381, 2007.

13 Steponaitis G, Skiriutė D, Kazlauskas A, Golubickaite I, Stakaitis R, Tamašauskas A and Vaitkienè P: High CHI3L1 expression is associated with glioma patient survival. Diagn Pathol 11: 42, 2016.

14 Thöm I, Andritzky B, Schuch G, Burkholder I, Edler L, Johansen JS, Bokemeyer C, Schumacher U and Laack E: Elevated pretreatment serum concentration of YKL-40 - an independent prognostic biomarker for poor survival in patients with metastatic nonsmall cell lung cancer. Cancer 116(17): 4114 $4121,2010$.

15 Liu X, Zhang Y, Zhu Z, Ha M and Wang Y: Elevated pretreatment serum concentration of YKL-40: An independent prognostic biomarker for poor survival in patients with colorectal cancer. Med Oncol 31(8): 85, 2014.

16 Chudecka-Głaz AM, Cymbaluk-Płoska AA, Menkiszak JL, Sompolska-Rzechuła AM, Tołoczko-Grabarek AI and RzepkaGórska IA: Serum HE4, CA125, YKL-40, BCL-2, cathepsin-1 and prediction optimal debulking surgery, response to chemotherapy in ovarian cancer. J Ovarian Res 7: 62, 2014.

17 Roslind A, Johansen JS, Christensen IJ, Kiss K, Balslev E, Nielsen DL, Bentzen J, Price PA and Andersen E: High serum levels of YKL-40 in patients with squamous cell carcinoma of the head and neck are associated with short survival. Int J Cancer 122(4): 857-863, 2008.

18 Junker N, Johansen JS, Andersen CB and Kristjansen PE: Expression of YKL-40 by peritumoral macrophages in human small cell lung cancer. Lung Cancer 48(2): 223-231, 2005.

19 Shao R, Taylor SL, Oh DS and Schwartz LM: Vascular heterogeneity and targeting: The role of YKL-40 in glioblastoma vascularization. Oncotarget 6(38): 40507-40518, 2015.

20 Rusak A, Jabłońska K and Dzięgiel P: The role of YKL-40 in a cancerous process. Postepy Hig Med Dosw (Online) 70(0): 1286-1299, 2016.

21 Kzhyshkowska J, Yin S, Liu T, Riabov V and Mitrofanova I: Role of chitinase-like proteins in cancer. Biol Chem 397(3): 231247, 2016.

$22 \mathrm{He}$ CH, Lee CG, Dela Cruz CS, Lee CM, Zhou Y, Ahangari F, Ma B, Herzog EL, Rosenberg SA, Li Y, Nour AM, Parikh CR, Schmidt I, Modis Y, Cantley L and Elias JA: Chitinase 3-like 1 regulates cellular and tissue responses via il-13 receptor $\alpha 2$. Cell Rep 4(4): 830-841, 2013.

23 Folkman J: Anti-angiogenesis: New concept for therapy of solid tumors. Ann Surg 175(3): 409-416, 1972.

24 Shao R: YKL-40 acts as an angiogenic factor to promote tumor angiogenesis. Front Physiol 4: 122, 2013.

25 Bednarek W: Markers and modulators of angiogenesis in ovarian cancer. Ginekol Pol 78(10): 754-763, 2007 (in Polish).

26 Carmeliet P and Jain RK: Molecular mechanisms and clinical applications of angiogenesis. Nature 473(7347): 298-307, 2011.

27 Gupta K and Zhang J: Angiogenesis: A curse or cure? Postgrad Med J 81(954): 236-242, 2005.

28 Goel S, Duda DG, Xu L, Munn LL, Boucher Y, Fukumura D and Jain RK: Normalization of the vasculature for treatment of cancer and other diseases. Physiol Rev 91(3): 1071-1121, 2011.

29 Lupo G, Caporarello N, Olivieri M, Cristaldi M, Motta C, Bramanti V, Avola R, Salmeri M, Nicoletti F and Anfuso CD:
Anti-angiogenic therapy in cancer: Downsides and new pivots for precision medicine. Front Pharmacol 7: 519, 2016.

30 Escorcia FE, Henke E, McDevitt MR, Villa CH, Smith-Jones P, Blasberg RG, Benezra R and Scheinberg DA: Selective killing of tumor neovasculature paradoxically improves chemotherapy delivery to tumors. Cancer Res 70(22): 9277-9286, 2010.

31 Libreros S and Iragavarapu-Charyulu V: YKL-40/CHI3L1 drives inflammation on the road of tumor progression. J Leukoc Biol 98(6): 931-936, 2015.

32 Francescone RA, Scully S, Faibish M, Taylor SL, Oh D, Moral L, Yan W, Bentley B and Shao R: Role of YKL-40 in the angiogenesis, radioresistance, and progression of glioblastoma. J Biol Chem 286(17): 15332-15343, 2011.

$33 \mathrm{Li}$ TM, Liu SC, Huang YH, Huang CC, Hsu CJ, Tsai CH, Wang SW and Tang CH: YKL-40-induced inhibition of mir-590-3p promotes interleukin-18 expression and angiogenesis of endothelial progenitor cells. Int J Mol Sci 18(5): pii: E920, 2017.

34 Remmele W and Stegner HE: Recommendation for uniform definition of an immunoreactive score (IRS) for immunohistochemical estrogen receptor detection (ER-ICA) in breast cancer tissue. Pathologe 8(3): 138-140, 1987 (in German).

35 Fox SB and Harris AL: Histological quantitation of tumour angiogenesis. APMIS 112(7-8): 413-430, 2004.

36 Vermeulen PB, Gasparini G, Fox SB, Colpaert C, Marson LP, Gion M, Beliën JA, de Waal RM, Van Marck E, Magnani E, Weidner N, Harris AL and Dirix LY: Second International Consensus on the methodology and criteria of evaluation of angiogenesis quantification in solid human tumours. Eur $\mathbf{J}$ Cancer 38(12): 1564-1579, 2002.

37 Pula B, Wojnar A, Witkiewicz W, Dziegiel P and PodhorskaOkolow M: Podoplanin expression in cancer-associated fibroblasts correlates with VEGF-C expression in cancer cells of invasive ductal breast carcinoma. Neoplasma 60(5): 516-524, 2013.

38 Królicka A, Kobierzycki C, Puła B, Podhorska-Okołów M, Piotrowska A, Rzeszutko M, Rzeszutko W, Rabczyński J, Domosławski P, Wojtczak B, Dawiskiba J and Dzięgiel P: Comparison of metallothionein (MT) and Ki-67 antigen expression in benign and malignant thyroid tumours. Anticancer Res 30(12): 4945-4949, 2010.

39 Hammond ME, Hayes DF, Dowsett M, Allred DC, Hagerty KL, Badve S, Fitzgibbons PL, Francis G, Goldstein NS, Hayes M, Hicks DG, Lester S, Love R, Mangu PB, McShane L, Miller K, Osborne CK, Paik S, Perlmutter J, Rhodes A, Sasano H, Schwartz JN, Sweep FC, Taube S, Torlakovic EE, Valenstein P, Viale G, Visscher D, Wheeler T, Williams RB, Wittliff JL, Wolff AC, Oncology ASoC and Pathologists CoA: American Society of Clinical Oncology/College of American Pathologists Guideline Recommendations for Immunohistochemical Testing of Estrogen and Progesterone Receptors in Breast Cancer (unabridged version). Arch Pathol Lab Med 134(7): e48-72, 2010.

40 Wolff AC, Hammond ME, Hicks DG, Dowsett M, McShane $\mathrm{LM}$, Allison $\mathrm{KH}$, Allred DC, Bartlett JM, Bilous M, Fitzgibbons P, Hanna W, Jenkins RB, Mangu PB, Paik S, Perez EA, Press MF, Spears PA, Vance GH, Viale G, Hayes DF, American Society of Clinical Oncology/College of American Pathologists: Recommendations for human epidermal growth factor receptor 2 testing in breast cancer: American Society of Clinical Oncology/College of American Pathologists Clinical Practice Guideline update. Arch Pathol Lab Med 138(2): 241256, 2014. 
41 Laemmli UK: Cleavage of structural proteins during the assembly of the head of bacteriophage t4. Nature 227(5259): 680-685, 1970.

42 Shao R, Hamel K, Petersen L, Cao QJ, Arenas RB, Bigelow C, Bentley B and Yan W: YKL-40, a secreted glycoprotein, promotes tumor angiogenesis. Oncogene 28(50): 4456-4468, 2009.

43 Shao R, Francescone R, Ngernyuang N, Bentley B, Taylor SL, Moral L and Yan W: Anti-YKL-40 antibody and ionizing irradiation synergistically inhibit tumor vascularization and malignancy in glioblastoma. Carcinogenesis 35(2): 373-382, 2014.

44 Mohammed RA, Ellis IO, Mahmmod AM, Hawkes EC, Green AR, Rakha EA and Martin SG: Lymphatic and blood vessels in basal and triple-negative breast cancers: Characteristics and prognostic significance. Mod Pathol 24(6): 774-785, 2011.

45 Ribatti D, Nico B, Ruggieri S, Tamma R, Simone G and Mangia A: Angiogenesis and antiangiogenesis in triple-negative breast cancer. Transl Oncol 9(5): 453-457, 2016.

46 Kim SH, Das K, Noreen S, Coffman F and Hameed M: Prognostic implications of immunohistochemically detected YKL-40 expression in breast cancer. World J Surg Oncol 5: 17, 2007.

47 Kang EJ, Jung H, Woo OH, Park KH, Woo SU, Yang DS, Kim AR, Lee JB, Kim YH, Kim JS and Seo JH: YKL-40 expression could be a poor prognostic marker in the breast cancer tissue. Tumour Biol 35(1): 277-286, 2014.
48 Roslind A, Knoop AS, Jensen MB, Johansen JS, Nielsen DL, Price PA and Balslev E: YKL-40 protein expression is not a prognostic marker in patients with primary breast cancer. Breast Cancer Res Treat 112(2): 275-285, 2008.

49 Jensen BV, Johansen JS and Price PA: High levels of serum HER-2/neu and YKL-40 independently reflect aggressiveness of metastatic breast cancer. Clin Cancer Res 9(12): 4423-4434, 2003.

50 Johansen JS, Christensen IJ, Riisbro R, Greenall M, Han C, Price PA, Smith K, Brünner N and Harris AL: High serum YKL40 levels in patients with primary breast cancer is related to short recurrence-free survival. Breast Cancer Res Treat $80(1)$ : 15-21, 2003.

51 Wan G, Xiang L, Sun X, Wang X, Li H, Ge W and Cao F: Elevated YKL-40 expression is associated with a poor prognosis in breast cancer patients. Oncotarget 8(3): 5382-5391, 2017.

Received March 30, 2018 Revised April 27, 2018 Accepted May 3, 2018 